\title{
Examining the entrepreneurial attitudes of Malaysian secondary school students
}

\begin{abstract}
Attitude as one of the most influential factors affecting entrepreneurial learning and behaviour has been under investigation to recognize how it can be improved through educational interventions. A study was conducted to determine the entrepreneurial attitude of 3,000 secondary school students in Malaysia. Findings indicate that students scored high on self-esteem cognition, achievement cognition, and achievement affect, but students had low mean scores in self-esteem behaviour, personal control affect and self-esteem affect. Moreover, there is no significant difference between the students' ethnic groups in terms of their self-esteem behaviour. This paper discusses that entrepreneurial attitude can be developed through proper learning exposure and entrepreneurship education opportunities. It also presents the implications of the study to improve the Malaysian education system and entrepreneurial attitude of students during the critical years of secondary school.
\end{abstract}

Keyword: Entrepreneurial Behaviour, Entrepreneurial Attitude, Secondary School Students 